\title{
CENTRO DE ARTES E ESPORTES UNIFICADOS E ESTUDO DE EXISTENTE CEU PROFO SAMOEL BRONDI, PRESIDENTE PRUDENTE - SP
}

Ana Caroline de Oliveira, Korina Aparecida Teixeira Ferreira da Costa

Universidade do Oeste Paulista - UNOESTE, Curso de Arquitetura e Urbanismo, Presidente Prudente, SP. E-mail: caroline18oliveira@hotmail.com

\section{RESUMO}

Os Centros Educacionais Unificados - CEUs, são equipamentos urbanos voltados para a ampliação da inserção social de comunidades carentes, no entanto apesar de não ser algo obrigatório a maioria dos CEUs seguem uma padronização arquitetônica no que diz respeito tanto ao programa de necessidades quanto da volumetria. Essa padronização pode apresentar em determinados casos tanto ponto positivo quanto negativo. $\mathrm{O}$ trabalho tem como objetivo explanar sobre o CEU em geral e analisar arquitetonicamente 0 CEU Profo Samoel Brondi, construído em Presidente Prudente - SP, buscando suas especificidades, erros e acertos e até que ponto a padronização dessas estruturas é viável. O presente trabalho utiliza a metodologia pautada na pesquisa qualitativa, por meio de análises, pesquisas e revisões bibliográficas.

Palavras-chave: CEU, Equipamento Urbano, Educação, Arquitetura Social, Padronização.

\section{CENTER FOR ARTS AND SPORTS UNIFIED AND STUDY OF EXISTING CEU PROFO SAMOEL BRONDI, PRESIDENTE PRUDENTE - SP}

\begin{abstract}
The Unified Educational Centers (CEUs) are urban equipment aimed at expanding the social insertion of needy communities, however, although it is not mandatory, most CEUs follow an architectural standardization regarding both the needs and volumetry programs. This standardization may in certain cases present both positive and negative points. The objective of this work is to explain CEU in general, to analyze the CEU Prof o Samoel Brondi, built in Presidente Prudente - SP, in an attempt to identify its specificities, errors and correctness, and to what extent the standardization of these structures is viable. The present work uses the methodology based on qualitative research, through analysis, research and bibliographical reviews.
\end{abstract}

Key words: CEU, Urban Equipment, Education, Social Architecture, Standardization.

\section{INTRODUÇÃO}

Os Centro de Artes e Esportes Unificados, são equipamentos públicos que atuam em áreas de vulnerabilidade social, objetivando reverter 0 quadro de desigualdade social, por meio de uma série de experiências educacionais, culturais, profissionalizantes para a comunidade em geral além de contribuir para uma melhor qualidade de vida e da paisagem urbana local. Dentro dessa temática, buscou-se explanar sobre o Centro de Artes e Esportes de uma maneira generalizada nos resultados do presente trabalho e analisar suas características arquitetônicas durante a análise de existente do CEU Profo Samoel Brondi apresentada na discussão dessa mesma pesquisa.
O objetivo geral do trabalho consiste em compreender acerca desse equipamento urbano e visualizar como o mesmo é colocado em prática através da análise de um existente, considerando suas características arquitetônicas, pontos positivos e negativos. A pesquisa se justifica pelo fato de que por meio das análises geradas podese pontuar as fragilidades encontradas e traçar novas diretrizes projetuais e construtivas para os Centros visando melhorias para seus usuários.

\section{METODOLOGIA}

O trabalho foi desenvolvido utilizando a metodologia de pesquisa qualitativa, uma vez que Godoy (1995) afirma que a pesquisa 
qualitativa não se apresenta como uma proposta rígida, dando ao pesquisador a possibilidade de diferentes perspectivas. Godoy (1995) ainda afirma que esse tipo de pesquisa analisa o objeto de maneira integrada, considerando as pessoas envolvidas e seus diferentes enfoques.

Com intuito de compreender melhor as questões que permeiam sobre os CEUs, foram utilizados levantamentos bibliográficos e analises in loco como forma de coleta de dados.

\section{RESULTADOS}

Os Centros de Artes e Esportes Unificados, foram criados em 2010 pelo governo federal e idealizados através da união de cinco ministérios com o intuito de desenvolver um projeto que integrasse em um único equipamento "atividades e serviços culturais, práticas esportivas e de lazer, formação e qualificação para o mercado de trabalho, serviços socioassistenciais, políticas de prevenção à violência e inclusão digital" (BRASIL. Ministério do Esporte, 2013), visando também a promoção da cidadania e modificação social das áreas onde são inseridos. Os CEUs fazem parte do Programa de Aceleração do Crescimento. De início eram chamados de Praça do PAC mas em 2013 foram rebatizados com o nome atual. (BRASIL, 2015; BRASIL, 2013; TSUKUMO, 2014).

Apesar de não ter utilização obrigatória, o governo federal disponibiliza três modelos de projetos de referência desenvolvidos por uma equipe multidisciplinar variando de acordo com o tamanho do terreno onde será implantado. Sendo assim, caso o município ou Distrito Federal opte por não seguir um dos modelos de referência deve se comprometer a manter no mínimo o programa básico proposto para cada um dos três modelos. (SIQUEIRA, 2014)

O modelo para terrenos com no mínimo $700 \mathrm{~m}^{2}$, é composto por um bloco multiuso de 5 pavimentos, contendo cineteatro, biblioteca, sala de informática, Centro de Referência de Assistência Social (Cras) e salas multiuso. Como está elevado por pilotis, o térreo se torna uma praça coberta de convivência e o projeto ainda conta com pista de skate, equipamentos de

ginástica, kit básico esportivo e jogos de mesa. (BRASIL, 2011; NAKAMURA, 2011).

O segundo modelo, para terrenos com no mínimo $3000 \mathrm{~m}^{2}$ é composto por dois blocos de um pavimento, o primeiro conta com biblioteca, sala de informática, cineteatro, salas de apoio e sanitários, enquanto o segundo é formado por salas multiuso, sanitário, cozinha e ambientes necessários para o funcionamento do Cras. Além disso, conta com pista de skate, pista de caminhada, quadra coberta, playground e equipamentos de ginástica. (BRASIL, 2011; SIQUEIRA 2014)

Por fim o terceiro modelo, para terrenos de no mínimo $7000 \mathrm{~m}^{2}$, se configura em um bloco térreo com dimensão maior do que os anteriores onde abriga sala de informática, biblioteca, salas multiuso, sanitário e vestiário, cineteatro com capacidade para até 120 pessoas e os ambientes necessários para funcionamento do Cras. Conta também com playground, pista de skate, quadra de areia, quadra poliesportiva coberta, espaço para terceira idade, equipamentos de ginástica, e pista de caminhada. (NAKAMURA, 2011)

A escolha das áreas para implantação dos equipamentos se dá através de levantamento das áreas de vulnerabilidade social em cidades com no mínimo 50 mil habitantes. É bastante comum que essas áreas façam parte ou sejam próximas de novos conjuntos habitacionais. A construção dos CEUs ocorre por meio de uma parceria entre governo federal e municipal. (BRASIL, 2015).

Por fim, sobre a aceitação dos Centros de Artes e Esportes Unificados pela comunidade, CEU (BRASIL, 2015) afirma que as experiências anteriores - em 2014 cerca de 100 unidades já estavam concluídas - apontam que quanto mais aberto e utilizado forem os espaços mais a comunidade irá cuidar e se apropriar, inibindo a depredação do equipamento.

\section{DISCUSSÃO}

O Centro de Artes e Esportes Unificados Professor Samoel Brondi, está locado em Presidente Prudente, município brasileiro no interior do Estado de São Paulo. Presidente Prudente conta com uma área de $562,107 \mathrm{~km}^{2}$, dos quais $16,56 \mathrm{~km}^{2}$ são de área urbana. O CEU Samoel Brondi, faz parte de uma das 360 propostas de construção que foram selecionadas em 2010 pelo Ministério da Cultura. A obra teve

início em 2012, e sua inauguração ocorreu em 2014, o terreno escolhido possui $12.260 \mathrm{~m}^{2}$ e está localizado no Parque Alvorada, região considerada como uma das áreas de 
vulnerabilidade e exclusão social da cidade.

(PRESIDENTE PRUDENTE, [2018?]).

Figura 01. Esquema de localização CEU Prof Samoel Brondi
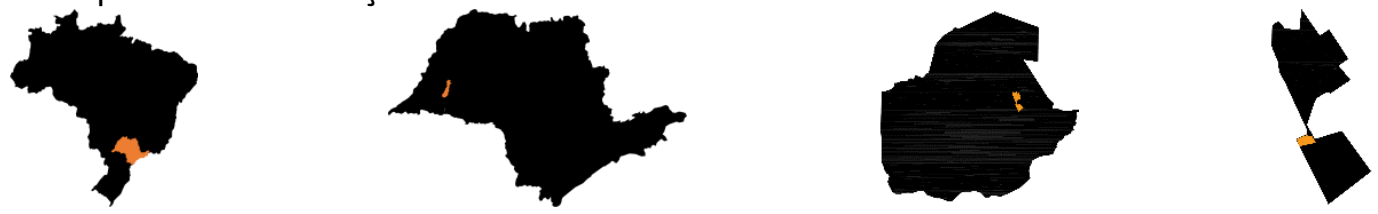

Fonte: A autora, 2018

A implantação é uma adaptação do projeto básico de referência. Conta com 4 acessos distribuídos ao longo do complexo. 0 acesso aos blocos edificados acontece por meio de rampas e escadas que vencem a topografia do terreno. Inicialmente a Praça CEU não contava com fechamento, porém após ser inaugurada a própria população local solicitou a colocação grades a fim de zelar do patrimônio que vinha sendo degradado.

Figura 2. Implantação CEU Professor Samoel Brondi

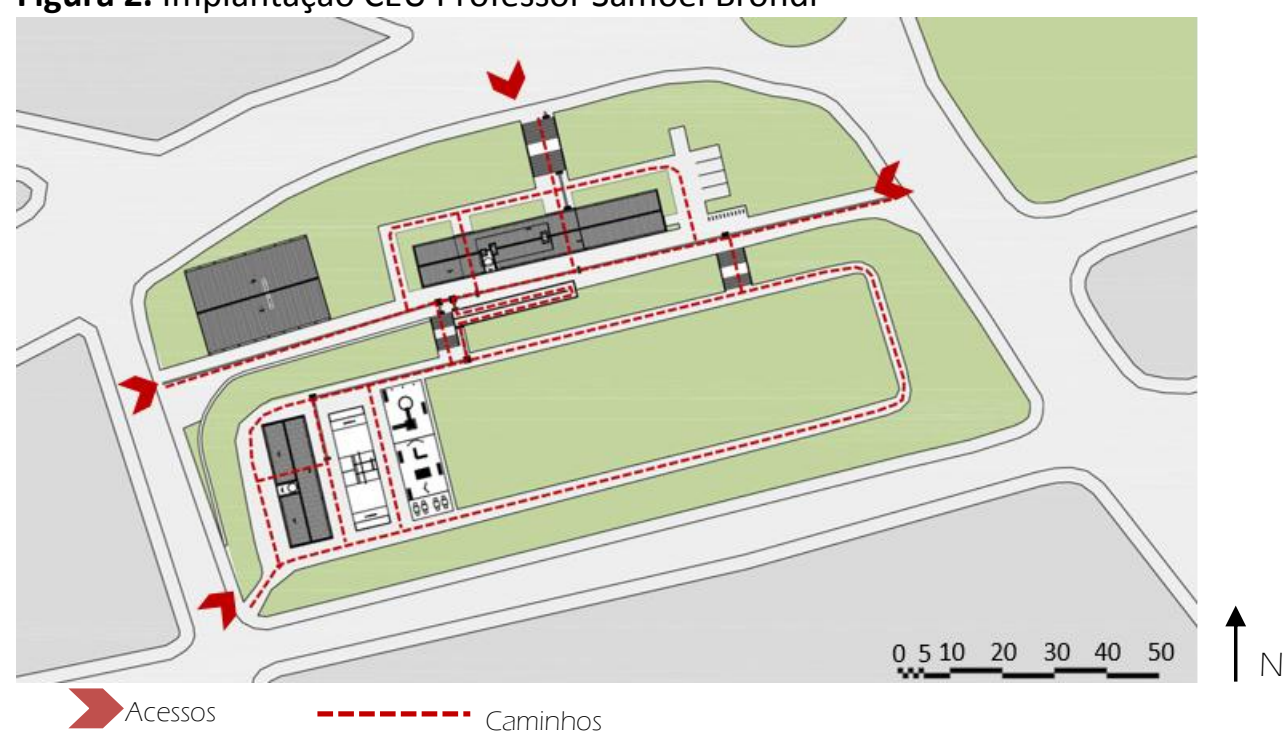

Fonte: A autora, 2018.

A geometria e inclinação acentuada do terreno foram os principais determinantes na alteração da locação dos blocos. Seu rearranjo configura uma praça alongada com pista de caminhada, ao lado também estão implantados o playground, a área de ginástica, mobiliário urbano e pista de skate. 
Figura 3. Topografia terreno 2011 e 2012

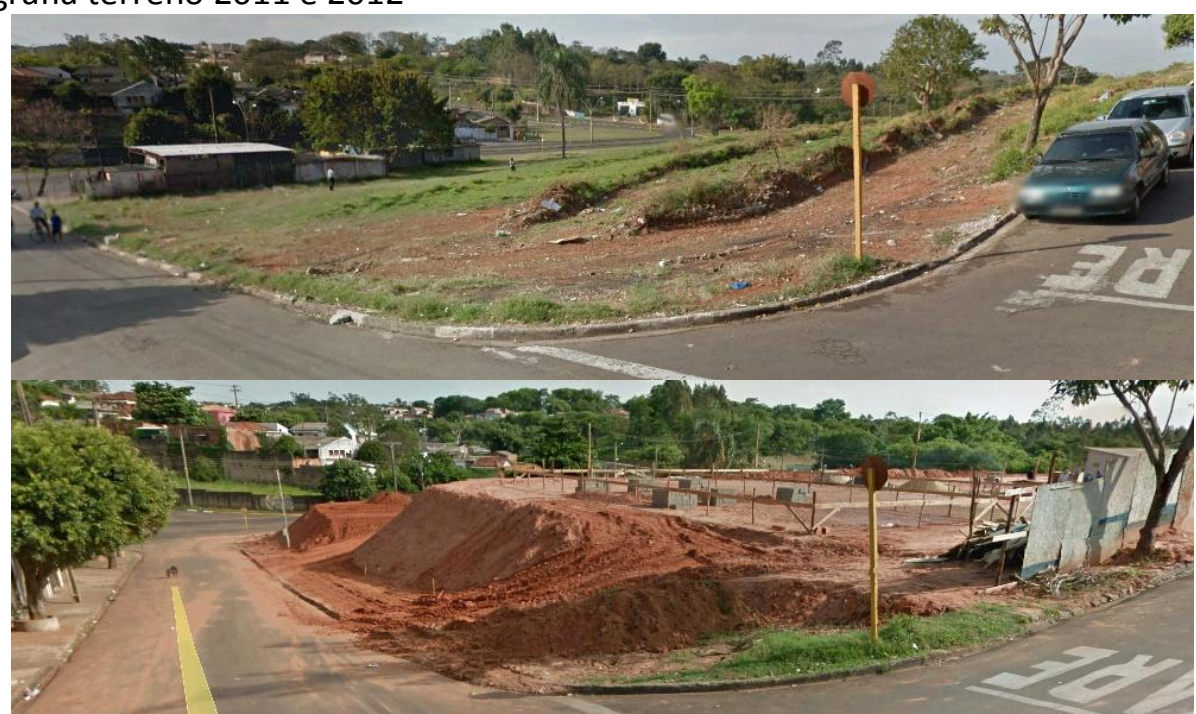

Fonte: Google Street View, 2018.

Nota: Modificado pela autora.

Tanto o edifício quanto a praça são acessíveis, contando com piso tátil e rampas de acessibilidade. $O$ piso tátil direcional foi utilizado na ausência ou na descontinuidade da linha-guia identificável, agindo como guia de caminhamento tanto nos ambientes internos quanto nos externos. Serve também para identificar caminhos preferenciais de circulação. Enquanto o piso tátil de alerta foi utilizado para sinalizar situações que envolvem risco de segurança, ou mudança de direções.

Figura 4. Elementos de acessibilidade CEU Prof. Samoel Brondi

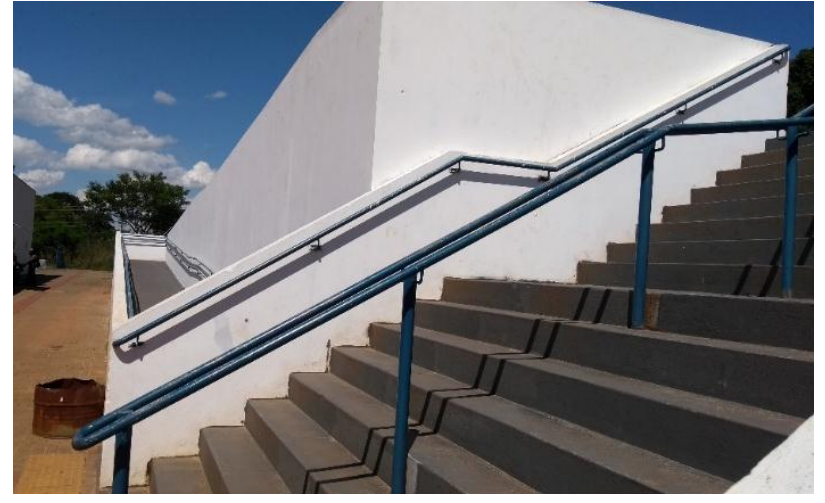

Fonte: A autora, 2018.

Os ambientes que acolhem as funções culturais e assistenciais previstas no programa do CEU estão organizadas em dois blocos edificados distintos. A parte destinada a esportes se

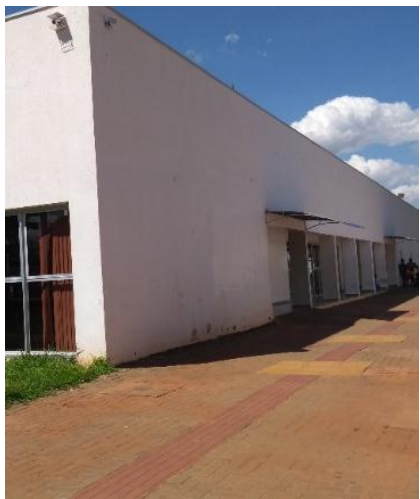

configura em pista de skate e quadra coberta, além de área de ginástica, pista de caminhada e playground. Como pode ser observado na imagem seguinte. 
Figura 5. Estudo de setorização CEU Professor Samoel Brondi

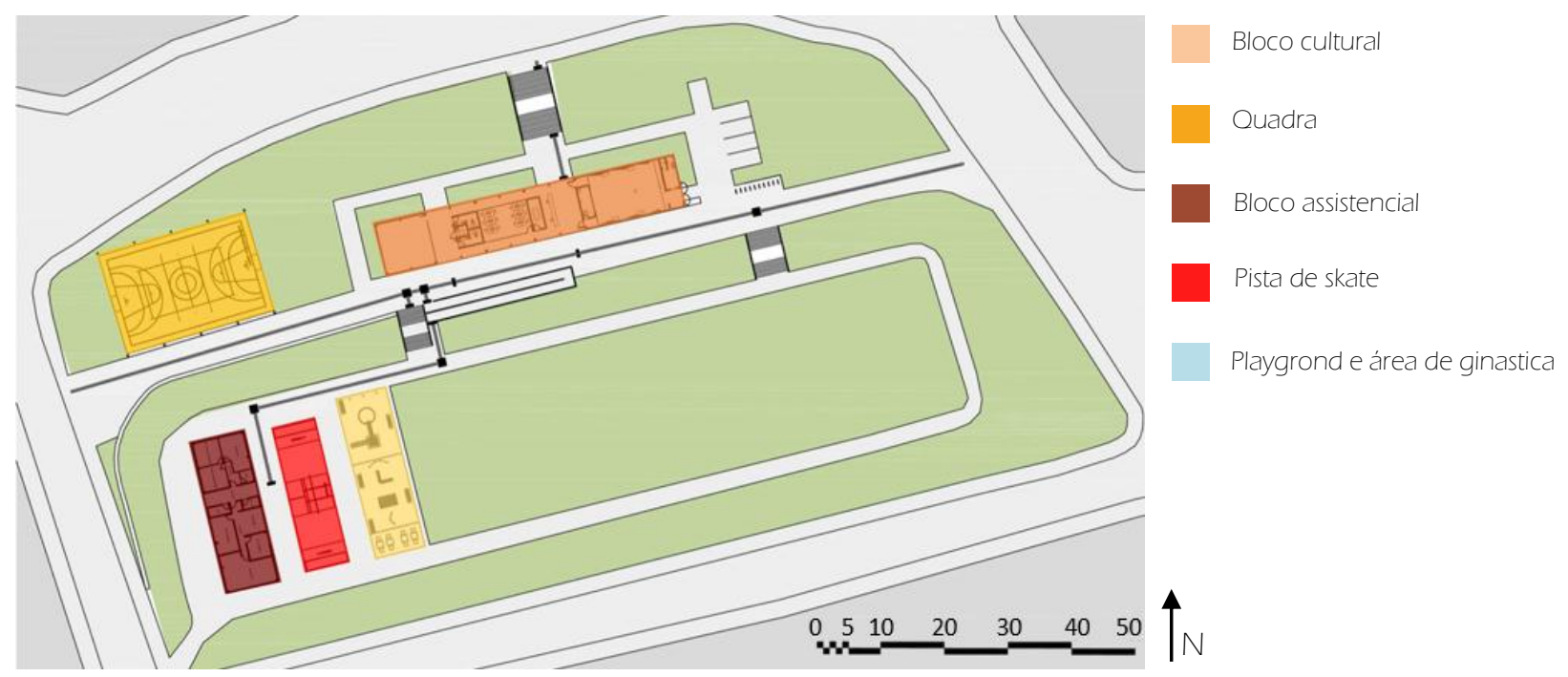

Fonte: A autora, 2018

O Bloco 1 denominado como bloco cultural, é o maior do complexo e reúne biblioteca, midiateca e cineteatro, além de sanitários, administração e salas de apoio. O

Figura 6. Bloco cultural CEU Professor Samoel Brondi

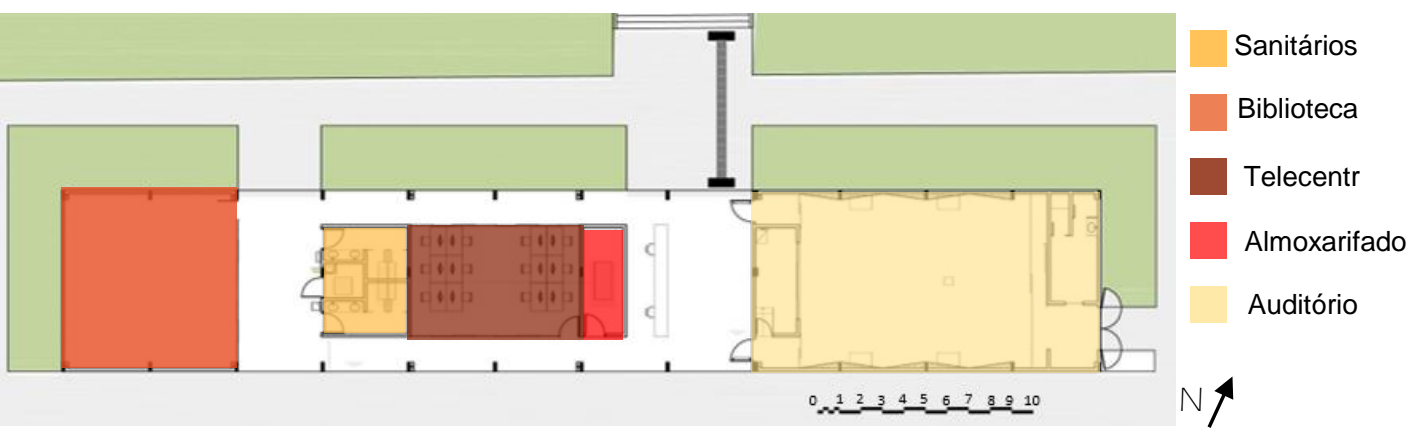

Fonte: A autora, 2018.

Enquanto o Bloco 2 abriga cômodos relacionados ao Centro de Referência em Assistência Social (CRAS) e salas multiuso. É também sede da Coordenadoria da Juventude, órgão vinculado ao Gabinete do Prefeito. Além disso, conta com quadra poliesportiva, pista de skate, playground, canteiros de leitura, academia e áreas verdes.

Figura 7. Bloco assistencial CEU Professor Samoel Brondi
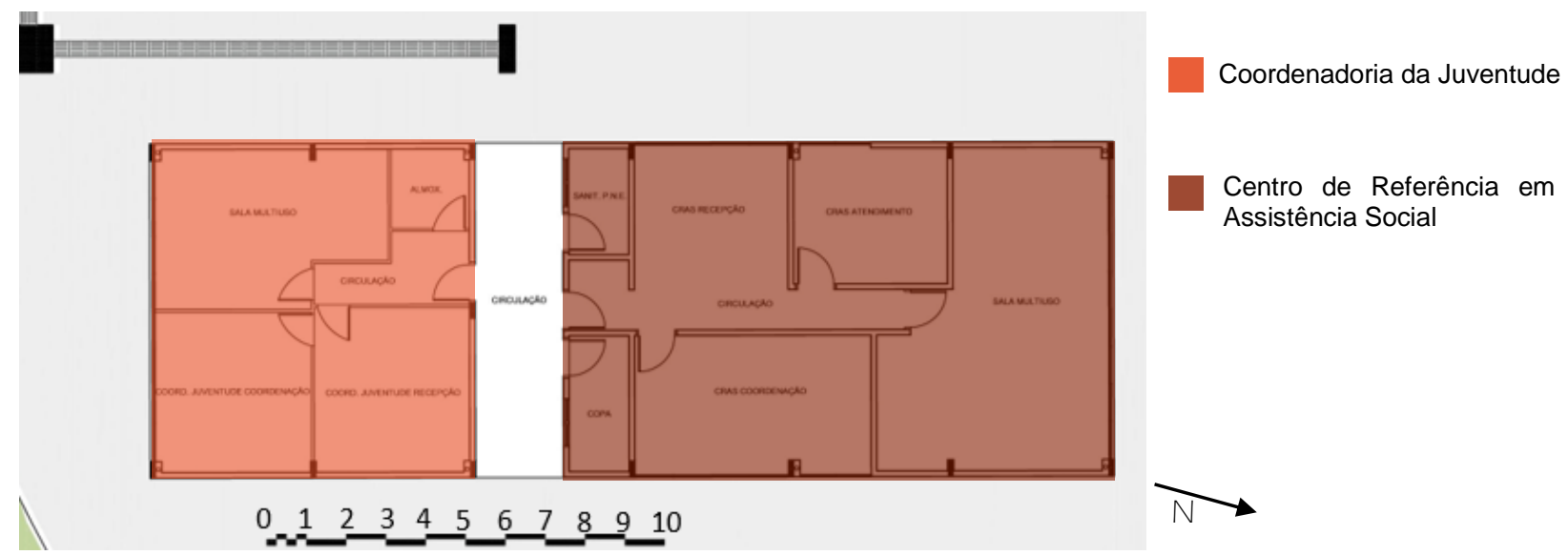

cineteatro tem disposição de palco e plateia livre, piso nivelado e a mobília não é fixa, o que permite criar diferentes configurações atendendo diversas atividades em um espaço multiuso.

Fonte: A autora, 2018 
Os blocos se caracterizam como dois volumes retangulares simples, utilizando alvenaria e esquadrias de vidro. A estrutura é convencional, em concreto armado moldado in loco. Os pilares têm seção retangular de $12 \mathrm{~cm} \mathrm{x}$ $40 \mathrm{~cm}$ e distam $4 \mathrm{~m}$ entre si ao longo das fachadas, criando vãos de $8 \mathrm{~m}$ correspondentes à largura dos ambientes internos. As coberturas dos blocos foram feitas utilizando telhas onduladas de fibrocimento com $6 \mathrm{~mm}$ de espessura e $9 \%$ de inclinação. Cada bloco possui uma área com iluminação zenital (clarabóia), onde foram utilizadas telhas de fibra de vidro ondulada. Já em relação a quadra tanto a cobertura, quanto o fechamento lateral foram feitos em telha metálica.

A direção predominante dos ventos no local é sudeste para noroeste. O terreno escolhido possui suas maiores dimensões voltadas para o norte/sul e não há construções existentes que influenciem no sombreamento. No entanto a implantação é problemática, uma vez que a biblioteca, locada no bloco 1 , possui uma fachada inteira em vidro voltada para a face oeste, recebendo todo o sol da tarde. Bem como o bloco 2, que foi implantado com sua maior fachada voltada também para oeste, apesar de não contar com aberturas nessa face, também recebe a sol da tarde.

Figura 8. Estudo conforto térmico CEU Professor Samoel Brondi

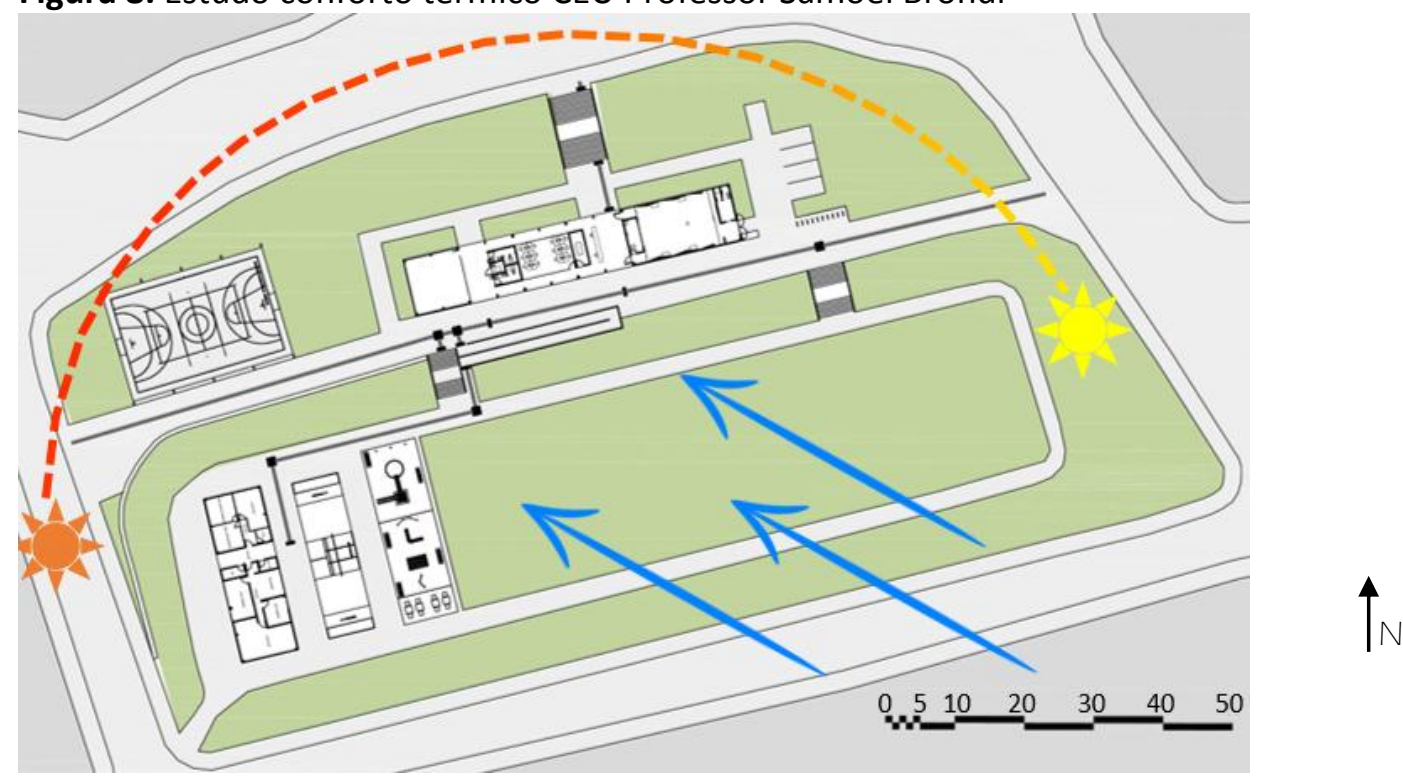

Fonte: A autora, 2018.

Por outro lado, os vazios destinados a circulação que cortam os blocos permitem a passagem do ar pelo edifício. Atualmente a praça alongada criada através da implantação dos blocos, possuem algumas árvores em tamanho de muda, acredita-se que quando atingirem o porte máximo crie um microclima que deixe o espaço mais agradável termicamente.

\section{CONCLUSÃO}

O presente trabalho permitiu uma melhor compreensão sobre os Centros de Artes e Esportes Unificados tanto em relação a sua idealização, funcionamento e objetivos entre outros aspectos em uma perspectiva teórica sobre os Centos, quanto da percepção de como eles realmente funcionam na prática, através da análise do CEU Profo Samoel Brondi.
No entanto fica claro que a padronização, apesar de permitir uma economia e rapidez construtiva, apresenta pontos negativos quando deixa de lado as especificidades de cada comunidade e terrenos escolhidos, como pode ser observado no Centro em estudo. Onde o projeto básico teve apenas alteração na forma de implantação dos blocos, vale ressaltar que o CEU Profo Samoel Brondi cumpre seu objetivo, porém tal atitude de projeto não favorece o conforto térmico dos usuários tanto nos edifícios quanto nas áreas adjacentes.

Dessa maneira apesar dos projetos básicos serem apropriados pelas comunidades $\mathrm{e}$ cumprirem seus objetivos, seria mais interessante que os CEUs tivessem sua linguagem arquitetônica e atitudes de projetos únicas, pensadas exclusivamente para a determinada região de implantação, visando melhorias para os 
usuários e dando realmente a sensação de pertencimento às comunidades.

\section{REFERÊNCIAS}

BRASIL. Centros de Artes e Esportes Unificados Conheça os Ceus: O programa. Brasília, 2011. Disponível em:

http://ceus.cultura.gov.br/index.php/conheca-osceus/o-programa>. Acesso em: 27 fev. 2018.

BRASIL. Ministério da Cultura. Conceito, Desafios e Potencialidades do PAC da Cultura, 2015. Brasília: ME, 2015 Disponível em: <http://ceus.cultura.gov.br/images/pdfs/reflexoe s_PAC_textos/Reflexoes_PAC_da_Cultur a_2014_textocompleto.pdf>. Acesso em: $27 \mathrm{fev}$. 2018.

BRASIL. Ministério do Esporte. Praça da Juventude: a inclusão social como exercício diário de cidadania. Brasília, 2013. Disponível em: <http://portal.esporte.gov.br/institucional/secret ariaExecutiva/pracaJuventude/sobre.jsp

Acesso em: 10 jul. 2018.

GODOY, A. S. Pesquisa Qualitativas: Tipos Fundamentais. Revista de administração de empresas. São Paulo, v. 35, n. 3, p. 20-29 Mai/Jun. $1995 . \quad$ Disponível em: <http://www.scielo.br/pdf/rae/v35n3/a04v35n3 >. Acesso em: 10 jul. 2018.

NAKAMURA, J. Praças de esportes e cultura. InfraestruturaUrbana, São Paulo, ed. 05, jul., 2011. Disponível em: <http://infraestruturaurbana17.pini.com.br/soluc oestecnicas/5/pracas-de-esportes-e-cultura-

224637-1.aspx>. Acesso em: 05 mar. 2018

PRESIDENTE PRUDENTE. Prefeitura Municipal. A cidade. Presidente Prudente, [2018?]. Disponível em:

<http://www.presidenteprudente.sp.gov.br/site/ acidade.xhtml>. Acesso em: 15 mar. 2018

SIQUEIRA, M. Conheça o projeto básico e veja a tabela detalhada das composições de custo da construção do CEU Dunas no Rio Grande do Sul. InfraestruturaUrbana, São Paulo, ed. 43, set., $2014 . \quad$ Disponível em: <http://infraestruturaurbana17.pini.com.br/soluc oes-tecnicas/43/conheca-o-projetobasico-e-vejaa-tabela-detalhada-das-327114-1.aspx>. Acesso em: 05 mar. 2018
TSUKUMO, I. T. L. Cartilha de orientação para ações de mobilização social nos Centros de Artes e Esportes Unificados - CEUs. Minc. 2. ed. rev. Atual. . Brasília, 2014

Recebido para publicação em 15/08/2018

Aceito em 24/08/2018 